\title{
Avaliação do estado nutricional do nitrogênio em batateira por meio de polifenóis e clorofila na folha
}

\author{
Fabrício Silva Coelho(1), Paulo Cezar Rezende Fontes ${ }^{(2)}$, Fernando Luiz Finger(2) e Paulo Roberto Cecon ${ }^{(3)}$
}

(1) Universidade Federal de Lavras, Departamento de Agricultura, Caixa Postal 37, CEP $37200-000$ Lavras, MG. E-mail: fabriciocoelho@dag.ufla.br (2)Universidade Federal de Viçosa (UFV), Departamento de Fitotecnia, Avenida P.H. Rolfs, s/no, Campus Universitário, CEP 36570-000 Viçosa, MG. E-mail: pacerefo@ufv.br, ffinger@ufv.br (3)UFV, Departamento de Estatística. E-mail: cecon@ufv.br

\begin{abstract}
Resumo - $\mathrm{O}$ objetivo deste trabalho foi avaliar o efeito de doses de $\mathrm{N}$ sobre índices fisiológicos relacionados à nutrição nitrogenada e verificar a possibilidade de estimar indiretamente os teores foliares de $\mathrm{N}$ em batata. Foram avaliados os índices de flavonóis (IFLV), de clorofila (ICHL) e de balanço de N (IBN), e as estimativas dos teores foliares de $\mathrm{N}$ foram realizadas aos 21 e 42 dias após a emergência, por meio do medidor portátil Dualex. O experimento foi conduzido de novembro de 2010 a fevereiro de 2011, em delineamento de blocos ao acaso, e os tratamentos consistiram de cinco doses de $\mathrm{N}\left(0,50,100,200\right.$ e $300 \mathrm{~kg} \mathrm{ha}^{-1} \mathrm{de} \mathrm{N}$, na forma de ureia) aplicadas em pré-plantio, com quatro repetições. Houve aumento no ICHL e no IBN e decréscimo no IFLV com o aumento das doses de N. Os índices determinados com o medidor Dualex correlacionaram-se com os teores de $\mathrm{N}$ e de clorofila extraível na quarta folha, bem como com o rendimento de tubérculos na safra. O Dualex pode ser utilizado para avaliar o estado nutricional de $\mathrm{N}$ em batateira e prognosticar a produtividade de tubérculos.
\end{abstract}

Termos para indexação: Solanum tuberosum, avaliação em tempo real, balanço nutricional, clorofila, compostos fenólicos, flavonóis.

\section{Evaluation of potato nitrogen status based on polyphenol and chlorophyll leaf content}

\begin{abstract}
The objective of this work was to evaluate the effect of $\mathrm{N}$ rates on physiological indexes related to nitrogen nutrition in potato, and to verify the possibility of indirectly estimating leaf $\mathrm{N}$ contents. Flavonol (FLVI), chlorophyll (CHLI), and the nitrogen balance (NBI) indexes were evaluated, and estimations of leaf $\mathrm{N}$ contents were made at 21 and 42 days after emergence using the Dualex leaf-clip instrument. The experiment was carried out from November 2010 to February 2011, in a randomized complete block design, with five $\mathrm{N}$ rates $(0,50,100$, 200 , and $300 \mathrm{~kg} \mathrm{ha}^{-1}$ of N, applied as urea) at pre-planting, and four replicates. There was an increase in CHLI and NBI and a decrease in FLVI with the increasing N doses. The indexes determined with Dualex were correlated with $\mathrm{N}$ and extractable chlorophyll content in the fourth leaf and with potato tuber yields. Dualex can be used to evaluate $\mathrm{N}$ nutritional status in potato plants, and for the prognosis of final tuber yield with readings.
\end{abstract}

Index terms: Solanum tuberosum, real-time evaluation, nutritional balance, chlorophyll, phenolic compounds, flavonols.

\section{Introdução}

O nitrogênio é um dos nutrientes de maior impacto na produtividade da cultura da batata (Solanum tuberosum L.), por afetar positivamente o crescimento do compartimento vegetativo da planta (Yin et al., 2003). O N participa com quatro átomos na molécula de clorofila e é componente dos ácidos nucléicos, além de ser indispensável na constituição de proteínas.

Ferramentas que permitam determinar, em tempo real, o estado nutricional de $\mathrm{N}$ das plantas, de forma rápida e a baixo custo, têm sido propostas (Samborski et al., 2009). Para a batata, são citadas análises com o uso de tabela de cor (Moreira et al., 2011), teor de nitrato no suco celular (Bélanger et al., 2003) e clorofilômetro Spad-502 (Uddling et al., 2007; Coelho et al., 2010).

Os compostos fenólicos, na camada epidérmica, produzidos pelo metabolismo secundário das plantas, correlacionam-se com fatores de estresse, como a baixa disponibilidade de N (Cerovic et al., 1999). Esses compostos são derivados das rotas do ácido chiquímico e dos fenilpropanoides, e podem agir como protetores de células vegetais por sequestrar espécies reativas de oxigênio produzidas pela radiação ultravioleta necessária à fotossíntese (Pietta, 2000). Com base nessa premissa, foi colocado no mercado o Dualex (Force-A, Orsay, França), um equipamento portátil para estimar, em tempo real e de forma não destrutiva, os índices

Pesq. agropec. bras., Brasília, v.47, n.4, p.584-592, abr. 2012 
isolados e combinados de clorofila e de flavonóis na folha.

O Dualex ("dual excitation") fornece informação do teor de polifenóis da cultura por meio da medição da absorção do ultravioleta (UV) da epiderme da folha pela excitação dupla da fluorescência da clorofila. Para isso, emite um feixe de luz de comprimento de onda a $375 \mathrm{~nm}$ (absorvido pelos polifenóis) e outro de referência a $650 \mathrm{~nm}$ (região do vermelho), que penetra na epiderme da folha (Goulas et al., 2004; Cartelat et al., 2005). Os feixes de raios UV não absorvidos pelos polifenóis excitam a clorofila no mesófilo foliar. Assim, a fluorescência emitida pela clorofila sob esta dupla excitação é proporcional à absorção de UV pela epiderme da folha, o que fornece indiretamente a concentração de polifenóis. Como a maioria dos compostos fenólicos está presente na epiderme, essa medida pode ser utilizada para estimar o teor de polifenóis global da folha (Goulas et al., 2004). $\mathrm{O}$ aparelho fornece no visor, em uma única medição na folha, o índice de clorofila (ICHL), o índice de flavonóis (IFLV) e o índice de balanço de nitrogênio (IBN), obtido pela relação entre ICHL e IFLV.

Dependendo da espécie e de calibração apropriada, a concentração de $\mathrm{N}$ na folha pode ser estimada indiretamente com o equipamento, pois há correlação negativa entre os teores de compostos fenólicos e de $\mathrm{N}$ na folha e correlação positiva com os teores de clorofila e o IBN. O Dualex tem sido utilizado para estimar a concentração de $\mathrm{N}$ na folha de diferentes espécies (Tremblay et al., 2010). Contudo, para a batata, ainda não há relatos de seu uso.

A avaliação do verde da folha de forma rápida e a baixo custo tornou-se mais fácil com os recentes avanços e o aperfeiçoamento de medidores portáteis e tem possibilitado sua utilização como critério de avaliação do estado nutricional de $\mathrm{N}$ nas plantas. Um desses medidores portáteis é o Spad-502, que vem sendo largamente pesquisado e utilizado com sucesso em várias culturas (Samborski et al., 2009). No entanto, em razão de limitações em seu uso (Hawkins et al., 2009), também têm sido propostas alternativas para melhorar a acurácia do aparelho em estimar as concentrações de clorofila, como o uso do peso específico da folha (Peng et al., 1993). Neste caso, a determinação desta variável é feita de maneira destrutiva e pouco aplicável na agricultura de precisão. Alternativamente, podem ser utilizadas medidas não destrutivas, como o uso do teor de polifenóis, também relacionado ao peso específico da folha (Goulas et al., 2004). Em milho, Tremblay et al. (2007) verificaram que, até 21 dias após a adubação, tanto o Spad-502 quanto o Dualex são eficientes em diagnosticar o estado de $\mathrm{N}$ nas plantas; porém, em estádios mais avançados da cultura, o Dualex não foi tão eficiente.

O objetivo deste trabalho foi avaliar o efeito de doses de $\mathrm{N}$ sobre índices fisiológicos relacionados à nutrição nitrogenada, bem como verificar a possibilidade de estimar indiretamente os teores foliares de $\mathrm{N}$ em batata.

\section{Material e Métodos}

O trabalho foi conduzido na Horta de Pesquisa do Departamento de Fitotecnia, da Universidade Federal de Viçosa, em Minas Gerais $\left(20^{\circ} 45^{\prime} \mathrm{S}\right.$ e $42^{\circ} 51^{\prime} \mathrm{W}$, a $693 \mathrm{~m}$ de altitude), entre novembro de 2010 e fevereiro de 2011. O clima, conforme a classificação de Köppen, é do tipo Cwa, tropical de altitude, com chuvas no verão e seca no inverno.

O solo da área experimental foi classificado como Argissolo Vermelho-Amarelo câmbico (Santos et al., 2006). A análise, para a caracterização físico-química do solo, na camada de $0-20 \mathrm{~cm}$, indicou: $\mathrm{pH}$ em água

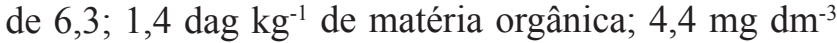
de $\mathrm{P} ; 39 \mathrm{mg} \mathrm{dm}{ }^{-3}$ de $\mathrm{K} ; 0,6 \mathrm{cmol}_{\mathrm{c}} \mathrm{dm}^{-3}$ de $\mathrm{Ca}^{2+}$;

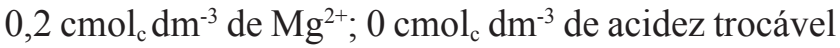
$\left(\mathrm{Al}^{3+}\right) ; 3,3 \mathrm{cmol}_{\mathrm{c}} \mathrm{dm}^{-3}$ de acidez potencial $\left(\mathrm{H}^{+}+\mathrm{Al}^{3+}\right)$; $21 \%$ de saturação por bases; $35 \%$ de areia; $14 \%$ de silte; e $51 \%$ de argila. Quarenta e cinco dias antes da instalação do experimento, foi realizada calagem com a aplicação de 2,5 $\mathrm{Mg} \mathrm{ha}^{-1}$ de calcário dolomítico (PRNT de $76 \%$ ) para elevar a saturação por bases para $60 \%$.

Utilizou-se o delineamento experimental de blocos ao acaso, com tratamentos constituídos de cinco doses de $\mathrm{N}\left(0,50,100,200\right.$ e $\left.300 \mathrm{~kg} \mathrm{ha}^{-1}\right)$ aplicadas em pré-plantio, com quatro repetições. Como fonte de $\mathrm{N}$, foi utilizada a ureia $(44 \%$ de $\mathrm{N})$. Cada parcela foi constituída de duas fileiras com doze plantas, espaçadas em $0,75 \mathrm{~m}$ entre fileiras e $0,25 \mathrm{~m}$ entre plantas, com 3,0 m de comprimento. As duas plantas das extremidades das fileiras foram utilizadas como bordadura. A adubação, feita manualmente no sulco de plantio, consistiu de $1.800 \mathrm{~kg} \mathrm{ha}^{-1}$ de superfosfato simples, $384 \mathrm{~kg} \mathrm{ha}^{-1}$ de cloreto de potássio, $200 \mathrm{~kg} \mathrm{ha}^{-1}$ de sulfato de magnésio, $10 \mathrm{~kg} \mathrm{ha}^{-1}$ de bórax, $10 \mathrm{~kg} \mathrm{ha}^{-1}$ 
de sulfato de zinco, $10 \mathrm{~kg} \mathrm{ha}^{-1}$ de sulfato de cobre e $0,5 \mathrm{~kg} \mathrm{ha}^{-1}$ de molibdato de sódio.

O plantio foi realizado em 10/11/2010, tendo-se utilizado batatas-sementes certificadas da cultivar Ágata, com massa média de $70 \mathrm{~g}$, previamente brotadas, com broto de aproximadamente 3,0 $\mathrm{cm}$. Não houve tratamento para quebra de dormência dos tubérculos. A amonta foi realizada 22 dias após a emergência das plantas (DAE).

Para o controle fitossanitário, foram feitas aplicações com os ingredientes ativos carbofuran, deltametrina, metamidofós, cimoxanil, mancozeb e oxicloreto de cobre. Aplicou-se a irrigação por aspersão convencional, no período da manhã, com lâmina de água estabelecida a partir da estimativa da evapotranspiração de referência e do coeficiente de cultura $(\mathrm{Kc})$. A estimativa de evapotranspiração de referência foi realizada pelo método de Penman-Monteith, tendo-se mantido o solo com umidade próxima à capacidade de campo. A água utilizada na irrigação apresentava $0,48 \mathrm{mg} \mathrm{L}^{-1}$ de $\mathrm{N}_{-\mathrm{NO}_{3}^{-}}^{-}$e $0,14 \mathrm{mg} \mathrm{L}{ }^{-1}$ de N-NH${ }_{4}^{+}$.

Aos 21 e 42 DAE, três plantas foram amostradas aleatoriamente para a realização das leituras com o Dualex. A medição foi feita no folíolo terminal da quarta folha expandida a partir do ápice da planta, em três plantas de cada parcela, entre 8 e $11 \mathrm{~h}$, tendo-se evitado leituras na nervura central da folha. Em cada folha, foram realizadas três leituras, a partir das quais foi calculada a média. A média das leituras representou o valor da parcela.

Posteriormente, as quartas folhas foram destacadas das plantas, colocadas em caixas de isopor contendo gelo e levadas ao laboratório para a determinação do teor de fenóis totais. Para isso, discos foliares, com peso aproximado de $1,5 \mathrm{~g}$ de matéria fresca, foram retirados das folhas e colocados em frascos de vidro contendo etanol $80 \%$, a $80^{\circ} \mathrm{C}$. Os compostos fenólicos totais $\mathrm{f}$ foram quantificados por meio do método espectrofotométrico de Folin-Ciocalteau, conforme Prince \& Butler (1977). A quantidade de fenóis totais de cada extrato foi obtida por meio de curva-padrão preparada com D-catequina e expressa como $\mathrm{mg}$ de D-catequina por $\mathrm{g}$ de matéria fresca. $\mathrm{O}$ restante das folhas foi colocado em estufa a $65^{\circ} \mathrm{C}$ para a determinação dos teores de $\mathrm{N}^{-\mathrm{NO}_{3}^{-}}$e de $\mathrm{N}^{-} \mathrm{NH}_{4}^{+}$, de acordo com Cataldo et al. (1975) e Jackson (1958), respectivamente. $\mathrm{O}$ teor de $\mathrm{N}$ total foi obtido pela soma do teor de $\mathrm{N}_{-} \mathrm{NO}_{3}^{-}$com o de $\mathrm{N}-\mathrm{NH}_{4}^{+}$.
Os dados foram submetidos à análise de variância e regressão, com uso do programa Saeg, versão 9.1 (SAEG, 2007). O modelo de regressão foi selecionado com base no significado biológico, na significância dos coeficientes de regressão pelo teste t, a $5 \%$ de probabilidade, e no maior coeficiente de determinação.

\section{Resultados e Discussão}

$\mathrm{O}$ teor de $\mathrm{N}$ total aumentou com as doses de $\mathrm{N}$ aplicadas, tendo seguido modelo linear, aos $21 \mathrm{DAE}$, e quadrático aos 42 DAE (Figura 1). Acréscimos nas concentrações de $\mathrm{N}$ na folha têm sido detectados com o aumento da quantidade da adubação nitrogenada. Esses aumentos tendem a atingir variações pronunciadas, que decrescem à medida em que se aumenta a quantidade aplicada de fertilizante (White \& Sanderson, 1983). Gil et al. (2002) e Coelho et al. (2010), ao avaliar as cultivares de batata Monalisa, Asterix e Ágata, verificaram que o teor de $\mathrm{N}$ na massa de matéria seca da quarta folha da batata, aos $21 \mathrm{DAE}$, aumentou de maneira quadrática com o incremento das doses de $\mathrm{N}$ em pré-plantio.

Houve efeito de doses de N nas características IFLV, teor de fenóis totais, ICHL, IBN e teor de $\mathrm{N}$ total na quarta folha a partir do ápice da batateira, aos $21 \mathrm{e}$ 42 DAE (Tabela 1).

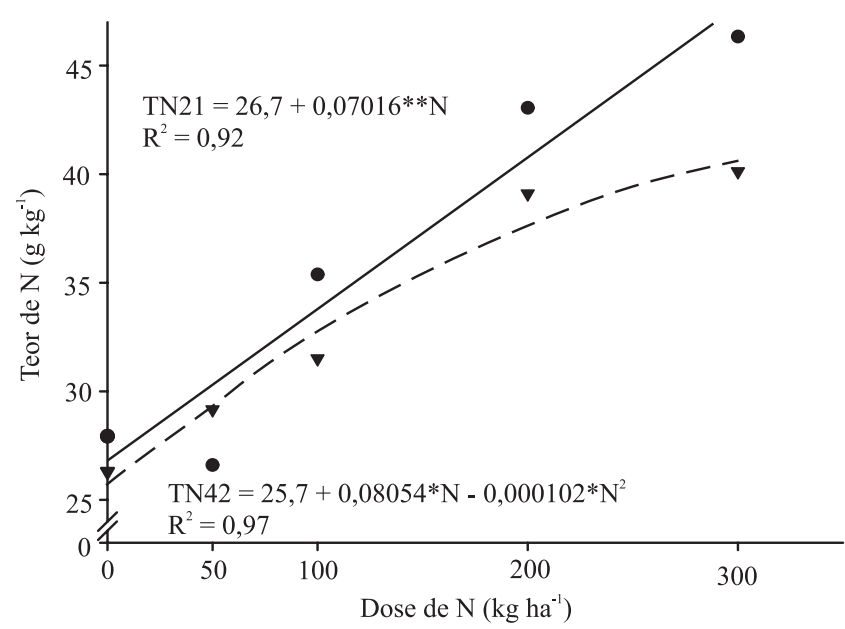

Figura 1. Teor de $\mathrm{N}$ total (TN) determinado na quarta folha a partir do ápice, aos 21 e aos 42 dias após a emergência, em função de doses de nitrogênio. ** e *Significativo pelo teste t, a 1 e $5 \%$ de probabilidade, respectivamente. 
O IFLV e o teor de fenóis totais decresceram significativamente com o aumento das doses de $\mathrm{N}$, tendo seguido um modelo quadrático (Figura 2). As plantas que não receberam a adubação nitrogenada apresentaram aumento de 35 e $55 \%$ no IFLV, em comparação às plantas que receberam $300 \mathrm{~kg} \mathrm{ha}^{-1} \mathrm{de}$ $\mathrm{N}$ aos 21 e 42 DAE, respectivamente. Decréscimos do teor de flavonóis, determinado com o Dualex, também foram verificados para trigo (Cartelat et al., 2005; Tremblay et al., 2010), milho (Huan et al., 2010) e brócolis (Fortier et al., 2010), com o aumento das doses de $\mathrm{N}$.

A produção e o acúmulo de polifenóis (flavonóis, taninos hidrolizáveis e "sideroxylonals") pelas plantas aumentam sob estresse, principalmente quando o uso do carbono para o crescimento ou reprodução das plantas é reduzido pela falta de nutrientes (Kandil et al., 2004). Quando o N limita o crescimento das plantas, há o acúmulo de carboidratos em seus tecidos de acordo com a hipótese do balanço de carbono/nutrientes (Bryant et al., 1983). Esse acúmulo direcionará o carbono para a síntese de metabólitos secundários, como os polifenóis e os terpenos (Hamilton et al., 2001).

$\mathrm{O}$ suprimento com $\mathrm{N}$ também influencia a síntese de proteínas e polifenóis, pois a rota biossintética dessas duas classes de compostos compartilham o mesmo precursor, o aminoácido fenilalanina (Jones \& Hartley, 1999). Sob condições adequadas de suprimento de N, a quantidade de fenilalanina alocada para a síntese de polifenóis diminui ou permanece constante, enquanto a alocada para a síntese de proteínas aumenta (Koricheva et al., 1998). Contrariamente, sob estresse de N, as plantas aumentam a alocação de fenilalanina para a síntese de polifenóis, em virtude da menor demanda de proteínas para o crescimento.

Houve aumento linear do ICHL em função das doses de N (Figura 3). Há relatos de que a intensidade do verde da folha, determinado com o clorofilômetro Spad-502, aumenta de forma quadrática com o aumento das doses de $\mathrm{N}$ até $300 \mathrm{~kg} \mathrm{ha}^{-1}$, em batateira (Coelho et al., 2010), diferentemente do verificado para o índice de clorofila, determinado com o Dualex no presente trabalho. Sob altas doses de N, o índice Spad tende a aumentar até certo ponto, a partir do qual se mantém invariável ou tende a declinar. Isso pode ser atribuído ao fato de o aparelho detectar, indiretamente, o aumento de $\mathrm{N}$ apenas quando está sendo incorporado em moléculas de clorofila, e não na forma livre, não incorporada $\left(\mathrm{N}-\mathrm{NO}_{3}^{-}\right)$, na qual o $\mathrm{N}$ se acumula quando há consumo de luxo (Argenta et al., 2001). Uma outra explicação seria a de que tenha ocorrido efeito deletério da dose excessiva de $\mathrm{N}$ sobre o conteúdo de clorofila.

O IBN determinado com o Dualex aumentou linearmente com o aumento das doses de N (Figura 4). De acordo com Cartelat et al. (2005), a relação entre o conteúdo de clorofila e flavonóis pode ser boa indicadora para avaliar o estado nutricional de $\mathrm{N}$ de plantas de trigo, pois, quando se trabalha com esta relação, é possível diminuir o problema do gradiente dos conteúdos de clorofila e de flavonóis existente na folha.

Ao utilizar os 20 pares de dados (cinco doses e quatro repetições), observou-se correlação linear

Tabela 1. Análise de variância para índice de flavonóis (IFLV), teor de fenóis totais (FT, $\mathrm{mg} \mathrm{g}^{-1}$ ), índice de clorofila (ICHL), índice de balanço de nitrogênio (IBN) e teor de $\mathrm{N}$ total (TN, $\mathrm{g} \mathrm{kg}^{-1}$ ), na quarta folha da batateira, determinados aos $21 \mathrm{e}$ 42 dias após a emergência.

\begin{tabular}{|c|c|c|c|c|c|c|}
\hline \multirow[t]{2}{*}{ Fonte de variação } & \multirow[t]{2}{*}{ GL } & \multicolumn{5}{|c|}{ Quadrados médios } \\
\hline & & IFLV & FT & ICHL & IBN & $\mathrm{TN}$ \\
\hline & & \multicolumn{5}{|c|}{ Aos 21 dias após a emergência } \\
\hline Doses & 4 & $0,64862 * *$ & $7,86718^{* *}$ & $66,91902 * *$ & $25,64764 * *$ & $310,1780 * *$ \\
\hline Bloco & 3 & $0,00184^{\mathrm{ns}}$ & $0,54248^{\mathrm{ns}}$ & $5,39254^{\mathrm{ns}}$ & $0,48167^{\mathrm{ns}}$ & $21,94450^{\mathrm{ns}}$ \\
\hline Resíduo & 12 & 0,13104 & 1,05002 & 4,00268 & 3,58929 & 9,80290 \\
\hline Média geral & & 3,33 & 7,17 & 35,16 & 10,99 & 35,86 \\
\hline \multirow[t]{2}{*}{$\mathrm{CV}(\%)$} & & 10,86 & 14,30 & 5,70 & 17,20 & 8,73 \\
\hline & & \multicolumn{5}{|c|}{ Aos 42 dias após a emergência } \\
\hline Doses & 4 & $1,59431 * *$ & $3,13864 * *$ & $48,46601 * *$ & $92,68917 * *$ & $149,54780 * *$ \\
\hline Bloco & 3 & $0,05867^{\mathrm{ns}}$ & $0,61061^{\mathrm{ns}}$ & $4,64001^{\mathrm{ns}}$ & $5,35645^{\mathrm{ns}}$ & $39,17600^{\mathrm{ns}}$ \\
\hline Resíduo & 12 & 0,10167 & 0,58052 & 4,96936 & 4,97291 & 26,12290 \\
\hline Média geral & & 2,93 & 3,96 & 36,43 & 13,77 & 33,24 \\
\hline CV $(\%)$ & & 10,90 & 19,20 & 6,10 & 16,20 & 15,40 \\
\hline
\end{tabular}

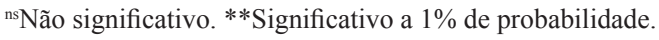


positiva entre ICHL e IBN, e negativa entre IFLV e teor de $\mathrm{N}$ (Tabela 2), o que confirma os resultados obtidos por Cartelat et al. (2005) e Tremblay et al. (2007). A relação verificada entre as leituras com o Dualex e os teores de $\mathrm{N}$ e de clorofila extraível indica que as leituras realizadas com este aparelho estimam adequadamente o grau de esverdeamento da folha de batata aos 21 e 42 DAE.

Houve correlação entre os índices avaliados com o Dualex e a produtividade comercial de tubérculos de batata, com maior valor aos 42 DAE. A correlação elevada entre essas variáveis é de grande importância para a diagnose precoce de nitrogênio, que possibilita a tomada de decisões em tempo hábil para possíveis adubações de cobertura com $\mathrm{N}$, sem o comprometimento da produção. Uma vez que a
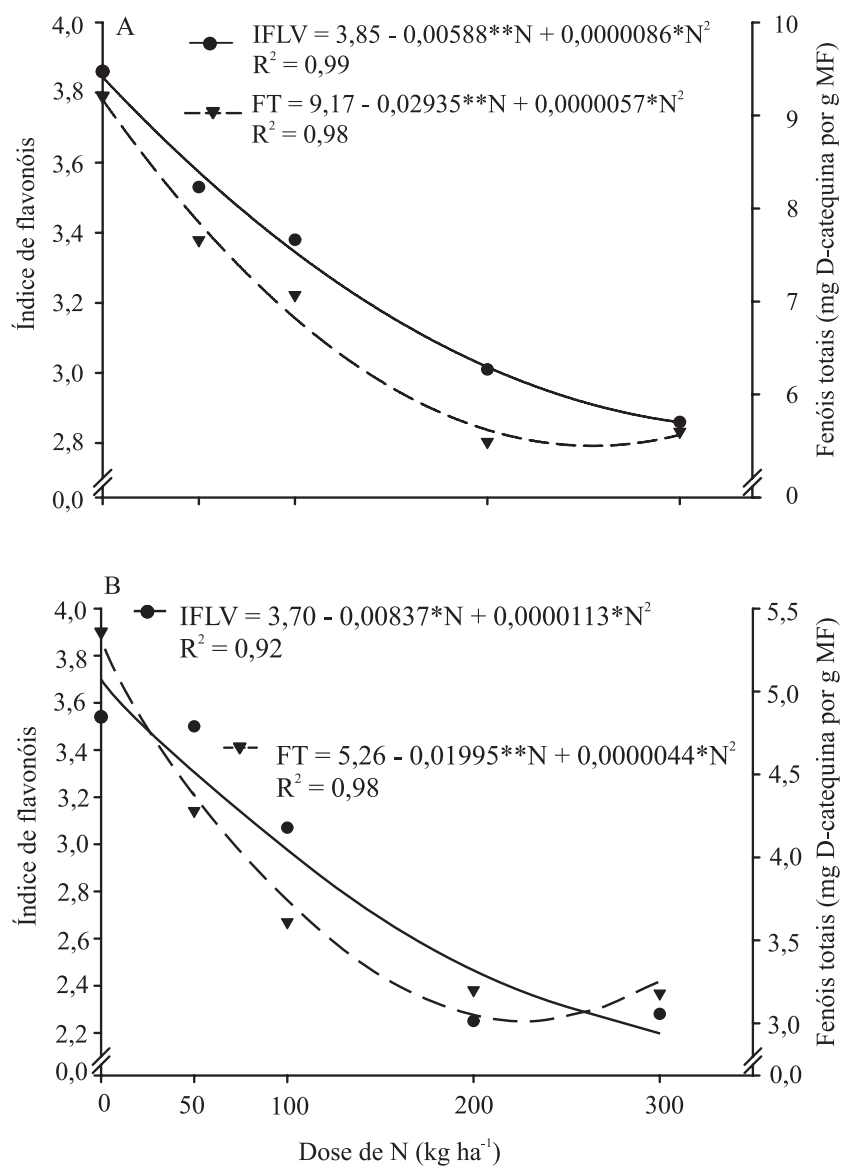

Figura 2. Índice de flavonóis (IFLV) determinado com o Dualex, e teor de fenóis totais (FT) na quarta folha a partir do ápice da batateira cultivar Ágata, aos 21 (A) e aos 42 (B) dias após emergência, em função de doses de nitrogênio. ** $\mathrm{e}$ *Significativo pelo teste t, a 1 e $5 \%$ de probabilidade, respectivamente. época de maior demanda de $\mathrm{N}$ pela batateira ocorre no início da tuberização, a correlação entre os índices determinados com o Dualex na quarta folha, aos 21 e $42 \mathrm{DAE}$, e a produção de tubérculos é importante, pois esse é o estádio mais indicado para a aplicação de $\mathrm{N}$ em cobertura, na batateira. Tremblay et al. (2010) verificaram que, apesar das leituras com Spad-502 e Dualex terem se correlacionado com a concentração de $\mathrm{N}$ na folha, os índices determinados com Dualex

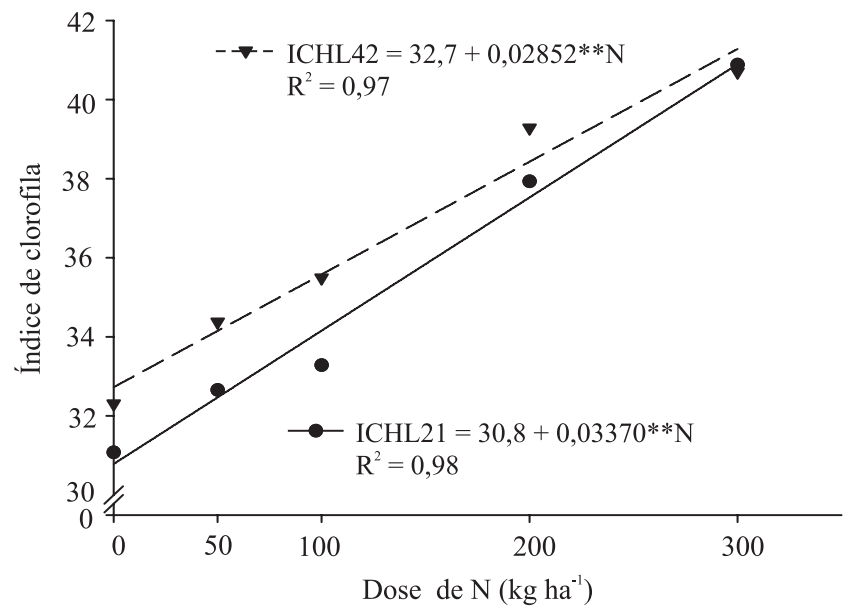

Figura 3. Índice de clorofila (ICHL) medido com o Dualex na quarta folha a partir do ápice da batateira cultivar Ágata, aos 21 e aos 42 dias após a emergência, em função de doses de nitrogênio. ${ }^{*}$ Significativo pelo teste t, a $1 \%$ de probabilidade.

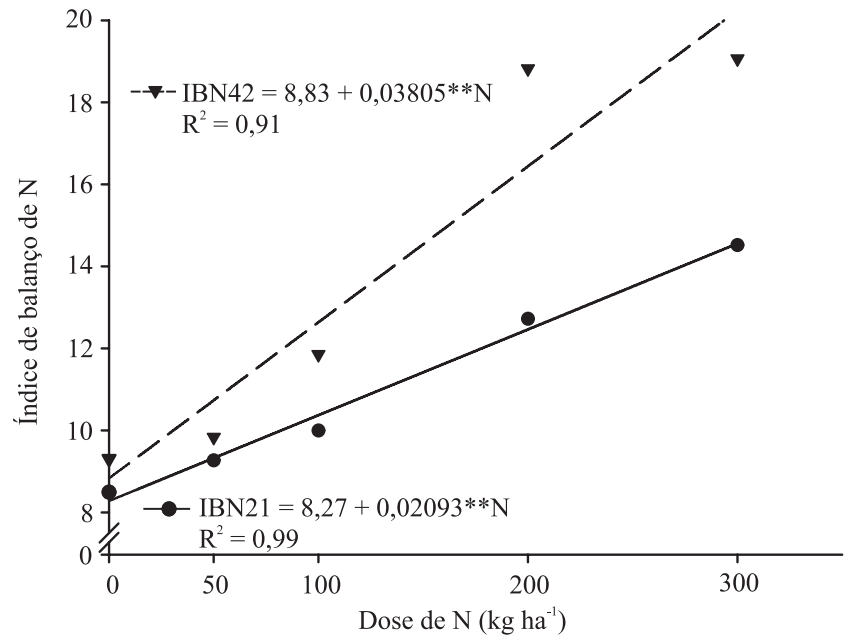

Figura 4. Índice de balanço de N (IBN) medido com o Dualex na quarta folha a partir do ápice da batateira cultivar Ágata, aos 21 e aos 42 dias após a emergência, em função de doses de nitrogênio. **Significativo pelo teste $\mathrm{t}$, a $1 \%$ de probabilidade. 
apresentaram maior correlação com a produtividade de grãos, e a relação entre o conteúdo de clorofila e de flavonóis foi a variável que melhor se correlacionou com essa característica. Os conteúdos de compostos fenólicos em folhas, obtidos com o Dualex, foram negativamente correlacionados com os valores da leitura com o Spad-502 e, também, com a produção de grãos de trigo (Cartelat et al., 2005). Isso provavelmente ocorreu pela competição na biossíntese e pela regulação metabólica de polifenóis e de proteínas, que têm o mesmo precursor, a fenilalanina.

De modo geral, os teores de $\mathrm{N}$ na quarta folha apresentaram menor correlação com o teor de clorofila extraível e com a produtividade comercial de tubérculos; portanto, apresentam potencial reduzido como indicadores do estado nutricional das plantas e, consequentemente, para a definição da dose de $\mathrm{N}$ na batateira. Esses resultados corroboram os de Coelho et al. (2010), que observaram que o teor de $\mathrm{N}$ na folha não é indicador sensível do estado nutricional da planta de batata e apresenta menor correlação com a produtividade do que a avaliação com o clorofilômetro Spad-502.

$\mathrm{O}$ teor de $\mathrm{N}$ na folha é característica eficiente para detectar deficiências, mas sua correlação com a produtividade das culturas é prejudicada pelo fenômeno do consumo de luxo, sob forma de nitrato. O consumo de luxo resulta em concentração de $\mathrm{N}$ na planta bem acima do nível em que incrementos nos teores de $\mathrm{N}$ na folha não são acompanhados por incrementos na produtividade (Rambo et al., 2011). Outros autores também verificaram

Tabela 2. Coeficientes de correlação linear de Pearson entre os índices de flavonóis, de clorofila e de balanço de $\mathrm{N}$, determinados aos 21 e 42 dias após a emergência, com o teor de $\mathrm{N}$ total, teor de clorofila extraível e produtividade comercial de tubérculos.

\begin{tabular}{|c|c|c|c|}
\hline Característica & $\begin{array}{l}\text { Teor de } \\
\mathrm{N} \text { total }\end{array}$ & $\begin{array}{l}\text { Teor de } \\
\text { clorofila }\end{array}$ & $\begin{array}{c}\text { Produtividade } \\
\text { comercial }\end{array}$ \\
\hline & \multicolumn{3}{|c|}{ Aos 21 dias após a emergência } \\
\hline Índice de flavonóis & $-0,73 * *$ & $-0,73 * *$ & $-0,72 * *$ \\
\hline Índice de clorofila & $0,89 * *$ & $0,68 * *$ & $0,80 * *$ \\
\hline Índice de balanço de $\mathrm{N}$ & $0,82 * *$ & $0,70 * *$ & $0,73 * *$ \\
\hline \multirow[t]{2}{*}{ Teor de $\mathrm{N}$ total } & - & $0,68 * *$ & $0,83 * *$ \\
\hline & \multicolumn{3}{|c|}{ Aos 42 dias após a emergência } \\
\hline Índice de flavonóis & $-0,79 * *$ & $-0,89 * *$ & $-0,83 * *$ \\
\hline Índice de clorofila & $0,72 * *$ & $0,86 * *$ & $0,83 * *$ \\
\hline Índice de balanço de $\mathrm{N}$ & $0,77 * *$ & $0,90 * *$ & $0,83 * *$ \\
\hline Teor de $\mathrm{N}$ total & - & $0,66 * *$ & $0,76 * *$ \\
\hline
\end{tabular}

**Significativo a $1 \%$ de probabilidade. que as medições efetuadas com Spad-502 e Dualex foram consideradas melhores indicadores do nível de $\mathrm{N}$ na planta do que o próprio teor deste nutriente na folha (Argenta et al., 2002; Cerovic et al., 2005).

A relação das leituras de IFLV (Figura 5), ICHL e IBN (Figura 6), determinados com o Dualex, com os teores de $\mathrm{N}$ na quarta folha, aos 21 e $42 \mathrm{DAE}$, permitiu o ajuste de modelos lineares e quadráticos, o que indica que as leituras obtidas com o aparelho podem ser utilizadas para estimar as concentrações de $\mathrm{N}$ determinadas pelo método padrão. Como o aparelho fornece leituras em unidades
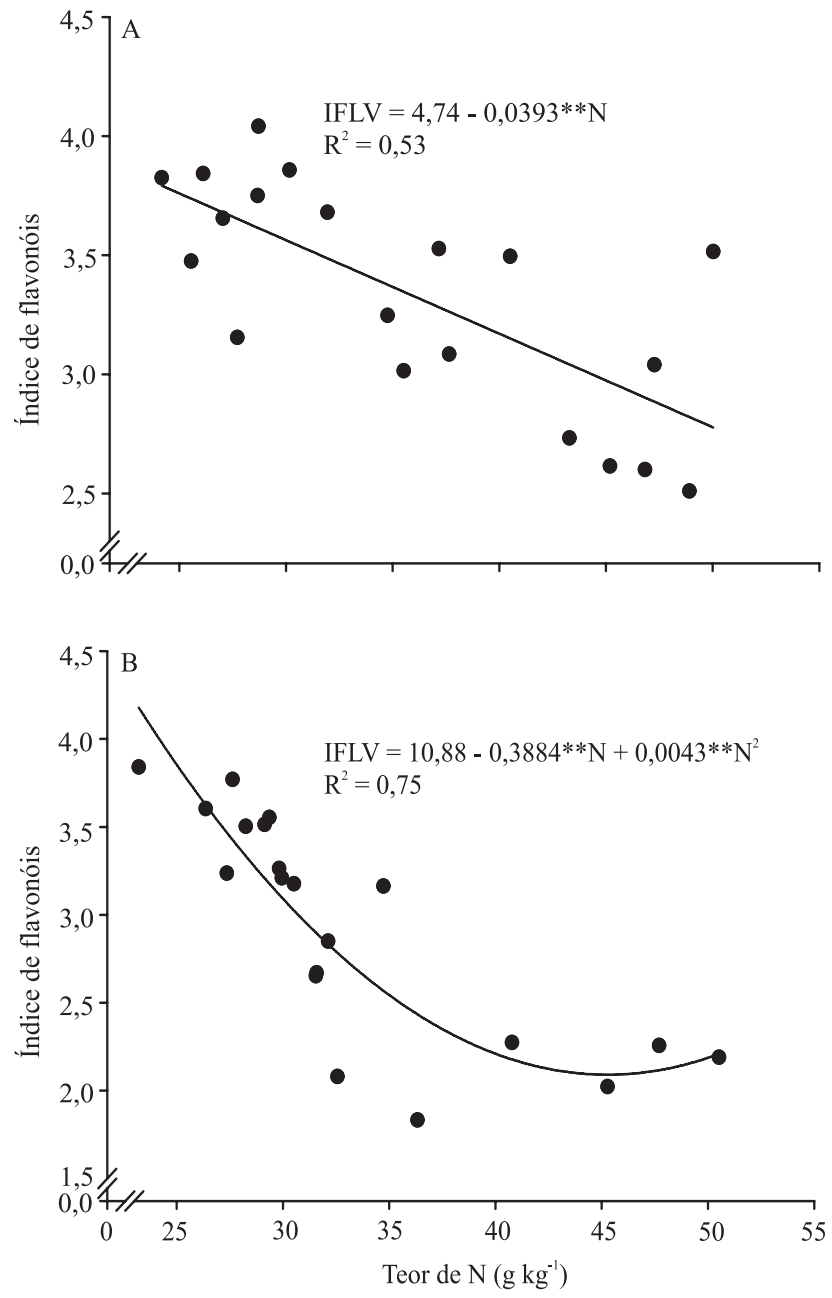

Figura 5. Relação do índice de flavonóis (IFLV) aos 21 (A) e 42 (B) dias após a emergência, medidos com o Dualex, com o teor de $\mathrm{N}$ total na quarta folha a partir do ápice da batateira cultivar Ágata, em função de doses de nitrogênio. **Significativo pelo teste $t$, a $1 \%$ de probabilidade. 

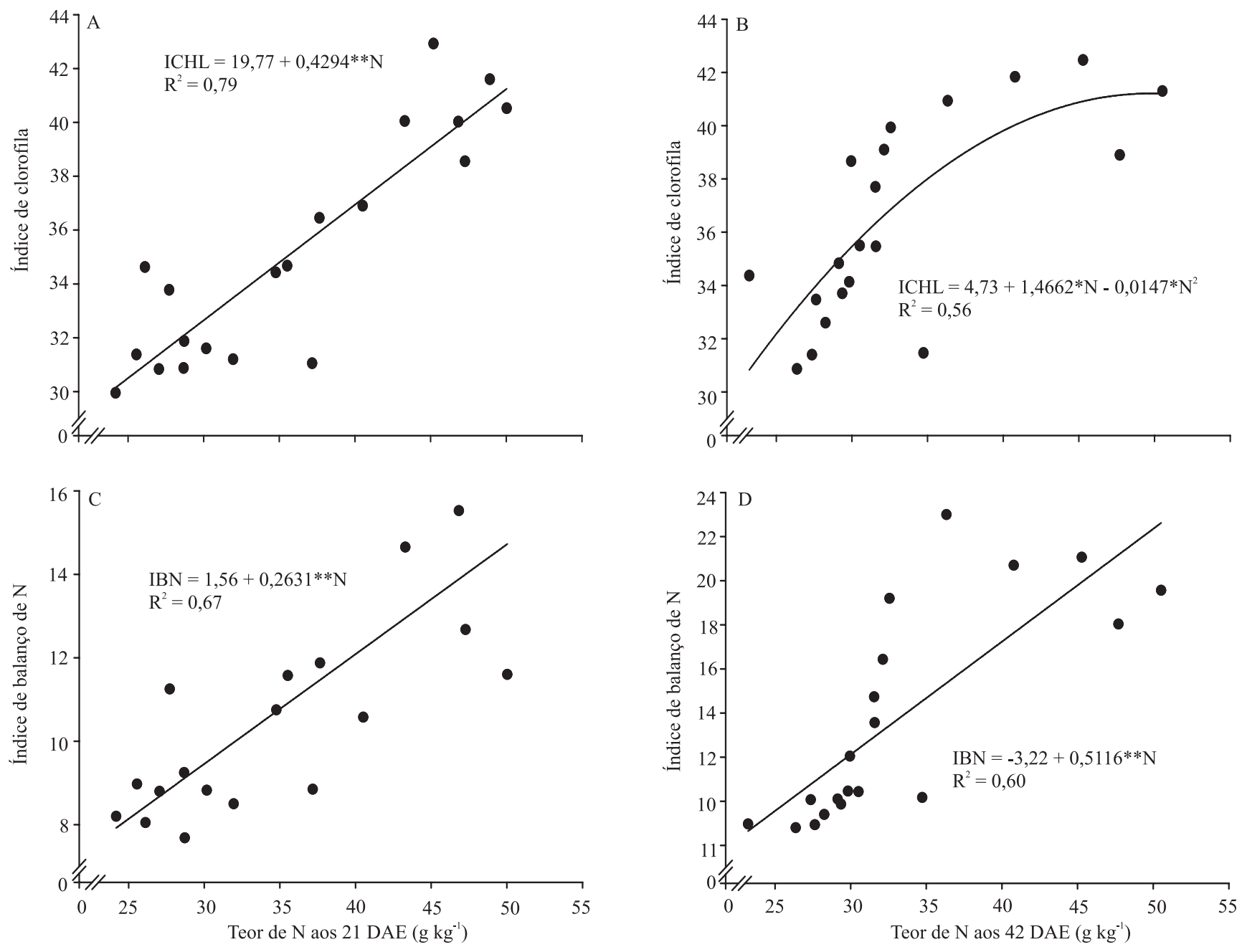

Figura 6. Relação dos índices de clorofila (ICHL) (A e B) e de balanço de N (IBN) (C e D), medidos com o Dualex, com o teor de $\mathrm{N}$ total na quarta folha a partir do ápice da batateira cultivar Ágata, respectivamente aos 21 (A e C) e aos 42 (B e D) dias após a emergência, em função de doses de nitrogênio. **e *Significativo pelo teste t, a 1 e $5 \%$ de probabilidade, respectivamente.

arbitrárias, testes de calibração, como o realizado no presente trabalho, são necessários para a validação do uso do Dualex. Em análise semelhante, Demotes-Mainard et al. (2008) obtiveram, para um conjunto de três espécies lenhosas, relações quadráticas entre as leituras com o Dualex e os teores de $\mathrm{N}$ na folha, com $\mathrm{R}^{2}$ de 0,85 a 0,53 .

\section{Conclusões}

1. Há correlação negativa entre o índice de flavonóis e os teores de nitrogênio e clorofila extraível na folha, e correlação positiva destes últimos com os índices de clorofila e de balanço do nitrogênio determinados com o Dualex.
2. A concentração de $\mathrm{N}$ na folha de batata pode ser estimada indiretamente com o Dualex, e o índice de balanço de $\mathrm{N}$ é o indicador mais preciso do estado nutricional da planta quanto ao nitrogênio.

3. Há correlação linear entre os valores dos índices determinados com o Dualex e a produção de tubérculos de batata, o que indica a possibilidade de seu uso para o prognóstico da produtividade.

\section{Agradecimentos}

Ao Conselho Nacional de Desenvolvimento Científico e Tecnológico e à Fundação de Amparo à Pesquisa do Estado de Minas Gerais, pelo apoio financeiro e pela concessão de bolsa. 


\section{Referências}

ARGENTA, G.; SILVA, P.R.F. da; BORTOLINI, C.G. Clorofila na folha como indicador do nível de nitrogênio em cereais. Ciência Rural, v.31, p.715-722, 2001.

ARGENTA, G.; SILVA, P.R.F. da; MIELNICZUK, J.; BORTOLINI, C.G. Parâmetros de planta como indicadores do nível de nitrogênio na cultura do milho. Pesquisa Agropecuária Brasileira, v.37, p.519-527, 2002.

BÉLANGER, G.; WALSH, J.R.; RICHARDS, J.E.; MILBURN, P.H.; ZIADI, N. Critical petiole nitrate concentration of two processing potato cultivars in Eastern Canada. American Journal of Potato Research, v.80, p.251-261, 2003.

BRYANT, J.P.; CHAPIN, F.S.; KLEIN, D.R. Carbon/nutrient balance of boreal plants in relation to vertebrate herbivory. Oikos, v.40, p.357-368, 1983.

CARTELAT, A.; CEROVIC, Z.G.; GOULAS, Y.; MEYER, S.; LELARGE, C.; PRIOUL, J.L.; BARBOTTIN, A.; JEUFFROY, M.H.; GATE, P.; AGATI, G.; MOYA, I. Optically assessed contents of leaf polyphenolics and chlorophyll as indicators of nitrogen deficiency in wheat (Triticum aestivum L.). Field Crops Research, v.91, p.35-49, 2005.

CATALDO, D.A.; HAROON, M.; SCHRADER, L.E.; YOUNES, V.L. Rapid colorimetric determination of nitrate in plant tissue by nitration of salicylic acid. Communications in Soil Science and Plant Analysis, v.6, p.71-80, 1975.

CEROVIC, Z.G.; CARTELAT, A.; GOULAS, Y.; MEYER, S. In-field assessment of wheat-leaf polyphenolics using the new optical leaf-clip Dualex. Precision Agriculture, v.5, p.243-249, 2005.

CEROVIC, Z.G.; SAMSON, G.; MORALES, F.; TREMBLAY, N.; MOYA, I. Ultraviolet-induced fluorescence for plant monitoring: present state and prospects. Agronomie, v.19, p.543-578, 1999.

COELHO, F.S.; FONTES, P.C.R.; PUIATTI, M.; NEVES, J.C.L.; SILVA, M.C. de. Dose de nitrogênio associada à produtividade de batata e índices do estado de nitrogênio na folha. Revista Brasileira de Ciência do Solo, v.34, p.1175-1183, 2010.

DEMOTES-MAINARD, S.; BOUMAZA, R.; MEYER, S.; CEROVIC, Z.G. Indicators of nitrogen status for ornamental woody plants based on optical measurements of leaf epidermal polyphenol and chlorophyll contents. Scientia Horticulturae, v.115, p.377-385, 2008.

FORTIER, E.; DESJARDINS, Y.; TREMBLAY, N.; BÉLEC, C.; CÔTÉ, M. Influence of irrigation and nitrogen fertilization on broccoli polyphenolics concentration. Acta Horticulturae, v.856, p.55-62, 2010.

GIL, P.T.; FONTES, P.C.R.; CECON, P.R.; FERREIRA, F.A. Índice SPAD para o diagnóstico do estado de nitrogênio e para o prognóstico da produtividade da batata. Horticultura Brasileira, v.20, p.611-615, 2002.

GOUlAS, Y.; CEROVIC, Z.G.; CARTELAT, A.; MOYA, I. Dualex: a new instrument for field measurements of epidermal ultraviolet absorbance by chlorophyll fluorescence. Applied Optics, v.43, p.4488-4496, 2004.
HAMILTON, J.G.; ZANGERL, A.R.; DELUCIA, E.H.; BERENBAUM, M.R. The carbon-nutrient balance hypothesis: its rise and fall. Ecology Letters, v.4, p.86-95, 2001.

HAWKINS, J.A.; SAWYER, J.E.; BARKER, D.W.; LUNDVALL, J.P. Using relative chlorophyll meter values to determine nitrogen application rates for corn. Agronomy Journal, v.99, p.1034-1040, 2009.

HUAN, Y.U.; HUA-SONG, W.U.; WANG, Z.-J. Evaluation of SPAD and Dualex for in-season corn nitrogen status estimation. Acta Agronomica Sinica, v.36, p.840-847, 2010.

JACKSON, M.L. Soil chemical analysis. Englewood Cliffs: Prentice Hall, 1958. 498p.

JONES, C.G.; HARTLEY, S.E. A protein competition model for phenolic allocation. Oikos, v.86, p.27-44, 1999.

KANDIL, F.E.; GRACE, M.H.; SEIGLER, D.S.; CHEESEMAN, J.M. Polyphenolics in Rhizophora mangle L. leaves and their changes during leaf development and senescence. Trees, v.18, p.518-528, 2004.

KORICHEVA, J.; LARSSON, S.; HAUKIOJA, E.; KEINÄNEN, M. Regulation of woody plant secondary metabolism by resource availability: hypothesis testing by means of meta-analysis. Oikos, v.83, p.212-226, 1998.

MOREIRA, M.A.; FONTES, P.C.R.; CECON, P.R.; ARAUJO, R.F. Índices para avaliar o estado de nitrogênio da batata multiplicada por distintos materiais propagativos. Revista Ceres, v.58, p.384$392,2011$.

PENG, S.; GARCIA, F.V.; LAZA, R.C.; CASSMAN, K.G. Adjustment of specific leaf weight improves chlorophyll meter's estimation of rice leaf nitrogen concentration. Agronomy Journal, v.85, p.987-990, 1993.

PIETTA, P.G. Flavonoids as antioxidants. Journal of Natural Products, v.63, p.1035-1042, 2000.

PRINCE, M.L.; BUTLER, L.G. Rapid visual estimation and spectrophotometric determination of tannin content of sorghum grain. Journal of Agricultural and Food Chemistry, v.25, p.1268-1273, 1977.

RAMBO, L.; SILVA, P.R.F. da; STRIEDER, M.L.; SILVA, A.A. da; SANGOI, L.; VIEIRA, V.M. Índices nutricionais de N e produtividade de milho em diferentes níveis de manejo e de adubação nitrogenada. Pesquisa Agropecuária Brasileira, v.46, p.390-397, 2011.

SAEG: Sistema para Análises Estatísticas. Versão 9.1. Viçosa: UFV, 2007.

SAMBORSKI, S.M.; TREMBLAY, N.; FALLON, E. Strategies to make use of plant sensors-based diagnostic information for nitrogen recommendations. Agronomy Journal, v.101, p.800-816, 2009.

SANTOS, H.G. dos; JACOMINE, P.K.T.; ANJOS, L.H.C. dos; OLIVEIRA, V.A. de; OLIVEIRA, J.B. de; COELHO, M.R.; LUMBRERAS, J.F.; CUNHA, T.J.F. (Ed.). Sistema brasileiro de classificação de solos. 2.ed. Rio de Janeiro: Embrapa Solos, 2006. $306 \mathrm{p}$. 
TREMBLAY, N.; WANG, Z.; BÉLEC, C. Evaluation of the Dualex for the assessment of corn nitrogen status. Journal of Plant Nutrition, v.30, p.1355-1369, 2007.

TREMBLAY, N.; WANG, Z.; BÉLEC, C. Performance of Dualex in spring wheat for crop nitrogen status assessment, yield prediction and estimation of soil nitrate content. Journal of Plant Nutrition, v.33, p.57-70, 2010.

UDDLING, J.; GELANG-ALFREDSSON， J.; PIIKKI， K.; PLEIJEL, H. Evaluating the relationship between leaf chlorophyll concentration and SPAD-502 chlorophyll meter readings. Photosynthesis Research, v.91, p.37-46, 2007.

WHITE, R.P.; SANDERSON, J.B. Effect of planting date, nitrogen rate, and plant spacing on potatoes grown for processing in Prince Edward Island. American Potato Journal, v.60, p.115-126, 1983.

YIN, X.Y.; LANTINGA, E.A.; SCHAPENDONK, A.H.C.M.; ZHONG, X. Some quantitative relationships between leaf area index and canopy nitrogen content and distribution. Annals of Botany, v.91, p.893-903, 2003.

Recebido em 5 de dezembro de 2011 e aprovado em 15 de março de 2012 